\title{
Zinc supplementation in chronic kidney disease of unknown aetiology in Sri Lanka: a pilot study. (ZisCKDu-P)
}

\author{
Abeysundara $\mathrm{PK}^{1}$, Nishad N², De Silva ST ${ }^{3}$, Dassanayake RT', Galabada DP5, Jayawardane UGW", \\ Premawardana NP ${ }^{6}$, Kumara GMSS${ }^{2}$, Dilani PM $^{3}$, Herath HMTD $^{3}$, Wijesinghe PS $^{3}$
}

Journal of the Ceylon College of Physicians, 2020, 51, 82-90

\begin{abstract}
Introduction: It was hypothesized that the antioxidant properties of zinc retard the progression of chronic kidney disease of unknown etiology in the North Central Province of Sri Lanka.
\end{abstract}

Methods: The pilot study was a randomized, placebo-controlled, single blinded, parallel group, single-center clinical trial with two arms ( $Z$ and $P$ ) and a 1:1 allocation ratio. Participants in group $Z$ $(n=20)$ received $60 \mathrm{mg}$ of elemental zinc daily, in the form of zinc sulfate, and group $P(n=21)$ received a starch tablet per day. Clinical, hematological parameters and kidney function were measured at the baseline and following three months of the intervention.

Results: A total of 86 CKDu patients were screened; only 35 males and 6 females were selected. Mean age and estimated glomerular filtration rate of the study population were $51.2 \pm 6.2$ years and $38.9 \pm 8.8 \mathrm{~mL} / \mathrm{min} / 1.73 \mathrm{~m}^{2}$ respectively. At the end of three months there was non-significant increase in urine protein creatinine ratio ( $Z$ arm: $65 \pm 54$ vs. $82 \pm 86 \mathrm{mg} / \mathrm{mmol} ; \mathrm{P}=0.46, \mathrm{P}$ arm: $72.4 \pm 113 \mathrm{vs}$. $120 \pm 209 \mathrm{mg} / \mathrm{mmol} ; \mathrm{P}=0.36$ ) and non-significant decline in estimated glomerular filtration rate $(Z$ arm: $40.9 \pm 10.4$ vs. $39.7 \pm 9.2 \mathrm{~mL} / \mathrm{min} / 1.73 \mathrm{~m}^{2} ; \mathrm{P}=0.31$, $P$ arm: $37.1 \pm 6.8$ vs. $36.4 \pm 10 \mathrm{~mL} / \mathrm{min} / 1.73 \mathrm{~m}^{2}$; $\mathrm{P}=0.31$ ) in both groups. Body mass index was significantly reduced $\left(23 \pm 4\right.$ vs. $22.7 \pm 3.9 \mathrm{~kg} / \mathrm{m}^{2}$; $\mathrm{P}=0.01)$ and diastolic blood pressure was significantly increased (78 \pm 6 vs. $86 \pm 10 \mathrm{mmHg}$; $\mathrm{P}=0.001$ ) in the placebo arm. Haemoglobin level showed a decline in the study group; $0.33 \pm 1 \mathrm{~g} / \mathrm{dl}$, while there was an increase in the placebo group, $0.34 \pm 0.7 \mathrm{~g} / \mathrm{dl},(P=0.02)$. There were no major side effects.

Conclusions: The change of urine protein: creatinine ratio and estimated glomerular filtration rate did not show a significant difference between the two groups. A future trial should test effectiveness of same dose of zinc for a similar duration of time in a larger sample. Extended follow-up of the study subjects for one year after the intervention would be useful to assess the long-term effects of zinc on kidney function and side effects.

\section{Introduction}

During the last two decades, Sri Lanka has experienced an increasing incidence of chronic kidney disease (CKD) of unknown aetiology (CKDu) in the North Central region dry zonal areas. The first cases of CKDu in Sri Lanka were recognized in the mid-1990s and the disease is predominantly seen in the North Central Province (NCP). ${ }^{1}$ It is hypothesized that CKDu has emerged as a result of consumption of water contaminated with heavy metals and toxins..$^{1,2}$ Synergistic effects of agrochemicals, algae toxins and heavy metals have been investigated as aetiological factors of this epidemic. ${ }^{3}$ Among individuals with CKDu in Sri Lanka, cadmium and arsenic levels in urine were found to be high. The urine cadmium concentration and CKDu stages showed a dose-effect relationship. ${ }^{2}$

\footnotetext{
${ }^{1}$ Ashraff Memorial Hospital, Kalmunai, Sri Lanka, ${ }^{2}$ Post Graduate Institute of Medicine, University of Colombo, Sri Lanka, ${ }^{3}$ Faculty of Medicine, University of Kelaniya, Sri Lanka, ${ }^{4}$ Provincial General Hospital, Kurunegala, Sri Lanka, ${ }^{5}$ District General Hospital, Polonnaruwa, Sri Lanka, ${ }^{6}$ District General Hospital, Monaragala, Sri Lanka.
}

Correspondence: PKA, e-mail: heshanprabathkularathne@yahoo.com

https://orcid.org/0000-0001-9485-846X

Received 19 August 2020, accepted 02 November 2020.

This is an open-access article distributed under the terms of the Creative Commons Attribution License, which permits unrestricted use, distribution, and reproduction in any medium, provided the original author and source are credited. 
Various studies have described different mechanisms of nephrotoxicity induced by heavy metals. ${ }^{4}$ Damage to the renal tubular cells by oxidative stress may explain the final common pathway of nephrotoxicity. ${ }^{5}$ Chronic exposure to zinc induce the production of metallothioneins which have protective antioxidant properties. Intestinal absorption of zinc is reduced in CKD. ${ }^{6}$ Therefore, there is a deficient state of zinc in CKD. ${ }^{7}$ Zinc deficiency increases the sensitivity to oxidative stress and increases the risk of chronic cadmium toxicity and nephropathy. ${ }^{8}$ Studies have not been conducted to assess serum zinc levels in CKDu patients in Sri Lanka. A community-based study among children aged 3-5 years in Southern Province of Sri Lanka revealed zinc deficiency in 57\% of males and $49 \%$ of females. ${ }^{9}$ Prevalence of zinc deficiency among adults living in NCP is unknown. Tolerable upper intake level of zinc is $40 \mathrm{mg}$ per day. ${ }^{10}$ Mean daily dietary intake of zinc in NCP of Sri Lanka is not known but it was found to be $10.8 \mathrm{mg}$ in rural India. ${ }^{11}$

We hypothesized that the anti-oxidant properties of zinc may retard the progression of CKDu. In patients with diabetic nephropathy supplementation of $50 \mathrm{mg}$ of elemental zinc for three months showed reduced urinary albumin excretion without any side effects. ${ }^{12}$ Effects of zinc on pre-diabetics were studied in a previous randomized controlled trial in Sri Lanka with no serious adverse effects noted during the 12 month follow-up period. ${ }^{13}$ But the effects of zinc on CKDu are unknown. Therefore, the aim of this pilot study was to assess the effects of zinc supplementation on progression of CKDu, to assess the feasibility of hypothesis testing main study, to explore trial design and to determine recruitment and retention.

\section{Methods}

\section{Trial design and participants}

The ZisCKDu-P study was a pilot, randomized, placebo-controlled, single blinded, parallel group, single-center clinical trial with two arms and a 1:1 allocation ratio. The study was designed to include a treatment arm and a placebo arm. CKD patients without recognized aetiological factors such as diabetes mellitus, chronic or severe hypertension, snake bite, glomerulonephritis or urological diseases, together with normal $\mathrm{HbA} 1 \mathrm{c}(<6.5 \%)$, blood pressure $<160 / 100 \mathrm{~mm} \mathrm{Hg}$ untreated or $<140 / 90 \mathrm{~mm} \mathrm{Hg}$ on up to two antihypertensive medications were defined as CKDu and recruited for the study (This definition was developed by the Scientific Committee of the National Research Program for CKDu launched by the World Health Organization and the Ministry of Healthcare and Nutrition of Sri Lanka ${ }^{14}$ ). Enrollment occurred over three months.
The inclusion criteria were CKDu patients with age between 18 to 60 years, eGFR between 30 and $60 \mathrm{ml} / \mathrm{min} / 1.73 \mathrm{~m}^{2}$ and the ability to provide informed consent and willing to complete follow-up for three months. The exclusion criteria were history of allergy to zinc, haemodialysis or peritoneal dialysis currently or within six months of recruitment, renal transplant recipient, pregnancy and breast feeding.

\section{Determination of sample size}

In this pilot study, 20 patients were included in the treatment group $(Z)$ and 21 patients in the placebo group $(P)$. A convenient sample size was used in the current pilot study. There were no similar studies conducted among CKDu patients in Sri Lanka to follow in sample size calculation. There was no intention to test the hypothesis. Therefore, the power of the study to test the hypothesis is undetermined.

\section{Recruitment}

Patients attending the renal clinic at the District General Hospital, Polonnaruwa who met the eligibility criteria of the study were invited to participate in the trial. The research assistant explained the study protocol, confirmed eligibility, provided the information leaflet, and obtained written informed consent. Participants were randomized to the intervention group $(Z)$ and the control group $(P),(1: 1)$ using a randomization table. All participants received instructions and coaching on how to follow a healthy lifestyle for CKD. At the baseline visit, the research assistant collected the demographic and other data using an interviewer administered questionnaire. At the recruitment and at the end of the follow up period of three months, their weight, height and blood pressure were measured. Weight, height and blood pressure were measured three times and mean values were calculated. All the measurements were done in a standardized manner by a trained health care professional using calibrated instruments.

Participants provided $10-\mathrm{ml}$ of blood and $30-\mathrm{ml}$ of urine samples at baseline and at three months followup to measure haemoglobin, serum creatinine and UPCR respectively.

\section{Intervention}

Participants who were randomized to group $Z$ received $60 \mathrm{mg}$ of elemental zinc, in the form of zinc sulfate, and group $P$ received one starch tablet per day as placebo for three months. The study participants were advised to take the pill every day before breakfast on empty stomach to enhance absorption and minimize interactions with routine drugs. 
Tolerable upper intake level (UL) of zinc is considered as $40 \mathrm{mg}$ per day in general population. UL is the highest level of daily nutrient intake that is likely to pose no risk of adverse health effects for almost all individuals. However, the UL is not meant to apply for individuals who are receiving zinc under medical supervision. Intake above the UL is appropriate for investigation within controlled clinical trials. A previous review stated that, clinical trials of doses above UL should not be discouraged, as these trials employ appropriate safety monitoring of trial subjects. ${ }^{10}$ In a previous study, a group of patients with diabetic nephropathy was treated with 50mg of zinc per day for 12 weeks without any observed side effects. ${ }^{12}$ Considering the above facts $60 \mathrm{mg}$ of elemental zinc in the form of zinc sulfate per day for 3 months, was used in the current study.

\section{Safety and adverse events}

Short term high dose exposure of zinc may cause upper gastrointestinal upset. ${ }^{15}$ Long term low dose exposure of zinc causes copper deficiency which leads to adverse events including anemia, myelopathy, and peripheral neuropathy. ${ }^{16,17}$ Persistent acute adverse effects for more than one week in a study subject were considered as the criterion for termination of a participant from the trial. Adverse effects for more than one week in $10 \%$ or more of the study subjects were considered to be the criterion for termination of the trial.

\section{Adherence}

The pill counting method was implemented. We employed numerous retention strategies to minimize loss to follow-up. The research assistant maintained continual contact with participants via telephone, email, and post to i) review the study protocol, ii) inquire about regimen tolerance and adherence, and iii) scheduled follow-up visits.

\section{Laboratory methods}

Serum creatinine, urine creatinine and calculation of estimated glomerular filtration rate (eGFR): Serum and urine samples were analyzed with Sarcosine oxidase enzymatic method using Mindray reagents. Measurement of serum creatinine was calibrated to be traceable to gas chromatographyisotope dilution mass spectrometry (GC- IDMS). eGFR was calculated with CKD-EPI 2009 equation.

Total protein in urine: Urine samples were analyzed with Pyrogalol red -- Molybdate method using Mindray reagents.
All these tests were run in, BS 800 Mindray Clinical Chemistry Analyzer. Third party Biorad internal quality control samples of two levels were run and it was made sure the results of internal quality control were within the acceptable range before running the samples. Third party external quality assurance program from Biorad clinical chemistry was performed monthly to assure accuracy of the results. Later $3^{\text {rd }}$ party Biorad urine chemistry program started.

\section{Randomization}

\section{Sequence generation}

Patients were randomized using a randomization table. Simple randomization without replacement was the technique used.

\section{Allocation concealment}

Patients were included and allocated sequential treatment, according to the randomization table that only the principal investigator had access.

\section{Blinding}

For practical reasons we could not blind the whole research staff to intervention allocation, but the participants were blinded to the intervention.

\section{Statistical methods}

Normality was assessed for serum creatinine levels using the Shapiro-Wilk test. Both groups showed a normal distribution. Continuous variables are presented as means \pm SDs. Categorical variables are presented as percentages. Intention-to treat analysis was used to compare the two groups, and all randomized patients were included. None of the participants was discontinued during the study period. The effects are presented as estimates with 95\% confidence intervals. A $P$ value $<0.05$ was considered statistically significant. Data were analyzed using SPSS (Version 16) statistical analyzing software for Windows.

\section{Ethical approval}

The ZisCKDu-P study was approved by the Ethics Review Committee, Faculty of Medicine, University of Kelaniya. Trial registration number: P/158/08/2018. All participants gave written informed consent.

\section{Trial registration}

The trial was registered as SLCTR/2019/001 at https://slctr.Ik/trials/slctr-2019-001, Universal trial number: U1111-1226-0963. 


\section{Modifications after trial registration}

Initially the trial was designed to assess the effects of zinc and selenium in progression of CKDu. But the effects of selenium were not assessed in the current study.

\section{Results}

\section{Recruitment and baseline assessment}

A total of 86 CKDu patients were screened; only 35 males and 6 females (41 participants) were eligible. Mean age and eGFR of the study population were $51.2 \pm 6.2$ years and $38.9 \pm 8.8 \mathrm{~mL} / \mathrm{min} / 1.73 \mathrm{~m}^{2}$ respectively. The recruitment period started in April
2019 and ended in June 2019. The follow-up ended in September 2019. The trial ended after the final patient had completed the three months of the intervention. A total of 20 patients were randomly assigned to the treatment group, and 21 to the placebo group. For each group, baseline clinical, hematological and biochemical characteristics are presented in Table 1. Mean ages of the intervention group and placebo group were $49.9 \pm 6.6$ years and $52.4 \pm 5.7$ years respectively, $P=0.2$. The patients were at CKD stage 3 . The CONSORT flow diagram (Figure 1) shows that during the three months of the intervention, none of the patients were discontinued. All analyses were performed on the originally assigned groups.

\section{Table 1. Baseline clinical, hematological and biochemical} characteristics of the study population

\begin{tabular}{|c|c|c|c|c|c|}
\hline & $\begin{array}{c}\text { Zinc Sulfate } \\
\quad(N=20)\end{array}$ & $S D$ & $\begin{array}{c}\text { Placebo } \\
(N=21)\end{array}$ & $S D$ & $P$ \\
\hline Age (years) & 49.9 & \pm 6.6 & 52.4 & \pm 5.7 & 0.2 \\
\hline \multicolumn{6}{|l|}{ Sex } \\
\hline Men & 17 & & 18 & & 0.6 \\
\hline Women & 3 & & 3 & & 1 \\
\hline $\mathrm{BMI}\left(\mathrm{Kg} / \mathrm{m}^{2}\right)$ & 21.5 & \pm 3 & 23 & \pm 4 & 0.2 \\
\hline Systolic blood pressure $(\mathrm{mmHg})$ & 122.9 & \pm 9.8 & 124.9 & \pm 11.9 & 0.56 \\
\hline Diastolic blood pressure $(\mathrm{mmHg})$ & 79.7 & \pm 5.6 & 78.5 & \pm 5.8 & 0.5 \\
\hline eGFR $\left(\mathrm{mL} / \mathrm{min} / 1.73 \mathrm{~m}^{2}\right)$ & 40.9 & \pm 10.4 & 37.1 & \pm 6.8 & 0.18 \\
\hline Urine/protein creatinine ratio $(\mathrm{mg} / \mathrm{mmol})$ & 65 & \pm 54 & 72.4 & \pm 113 & 0.8 \\
\hline Haemoglobin (g/dl) & 12 & \pm 1 & 12.4 & \pm 1.75 & 0.37 \\
\hline Ischemic heart disease & 1 & & - & & - \\
\hline Smoking & 2 & & 1 & & 0.54 \\
\hline Family history of CKD & 3 & & 5 & & 0.8 \\
\hline \multicolumn{6}{|l|}{ Medicines used during the study period } \\
\hline ARB & 6 & & 8 & & 0.21 \\
\hline Statin & 12 & & 9 & & 0.34 \\
\hline Calcium Carbonate & 15 & & 13 & & 0.31 \\
\hline 1-alpha CCF & 17 & & 19 & & 0.28 \\
\hline Furosemide & 4 & & 5 & & 0.7 \\
\hline Sadium Bicarbonate & 16 & & 14 & & 0.46 \\
\hline Ferous sulfate & 13 & & 10 & & 0.33 \\
\hline
\end{tabular}




\begin{tabular}{lrrrr} 
& Vitamin C & 13 & 10 & 0.33 \\
& Allopurinol & 7 & 3 & 0.14 \\
& Omeprazole & 9 & 9 & 0.9 \\
& Domperidone & 12 & 13 & 0.74 \\
& Lactulose & 2 & 3 & 0.63 \\
& ND-CHB & 4 & 3 & 0.67 \\
& D-CHB & 2 & - & 0.42 \\
& Hydrochlorothiazide & 5 & 3 & \\
& Aspirin & 1 & - & 0.63 \\
& Beta Blocker & 2 & 3 & 0.46 \\
\hline ARB & Prazosin & 4 & 6 & \\
1-Alpha CCF & - Angiotensin Receptor Blockers & & \\
ND-CHB & - 1-Alpha Cholecalciferol & & & \\
D-CHB & - Non Dihydropyridine Calcium Channel Blockers & & \\
BMI & - Dihydropyridine Calcium Channel Blockers & & \\
CKD & - Body Mass Index & &
\end{tabular}

Enrollment

Assessed for eligibility $(n=86)$

45 subjects did not meet eligibility criteria or were not interested in participating

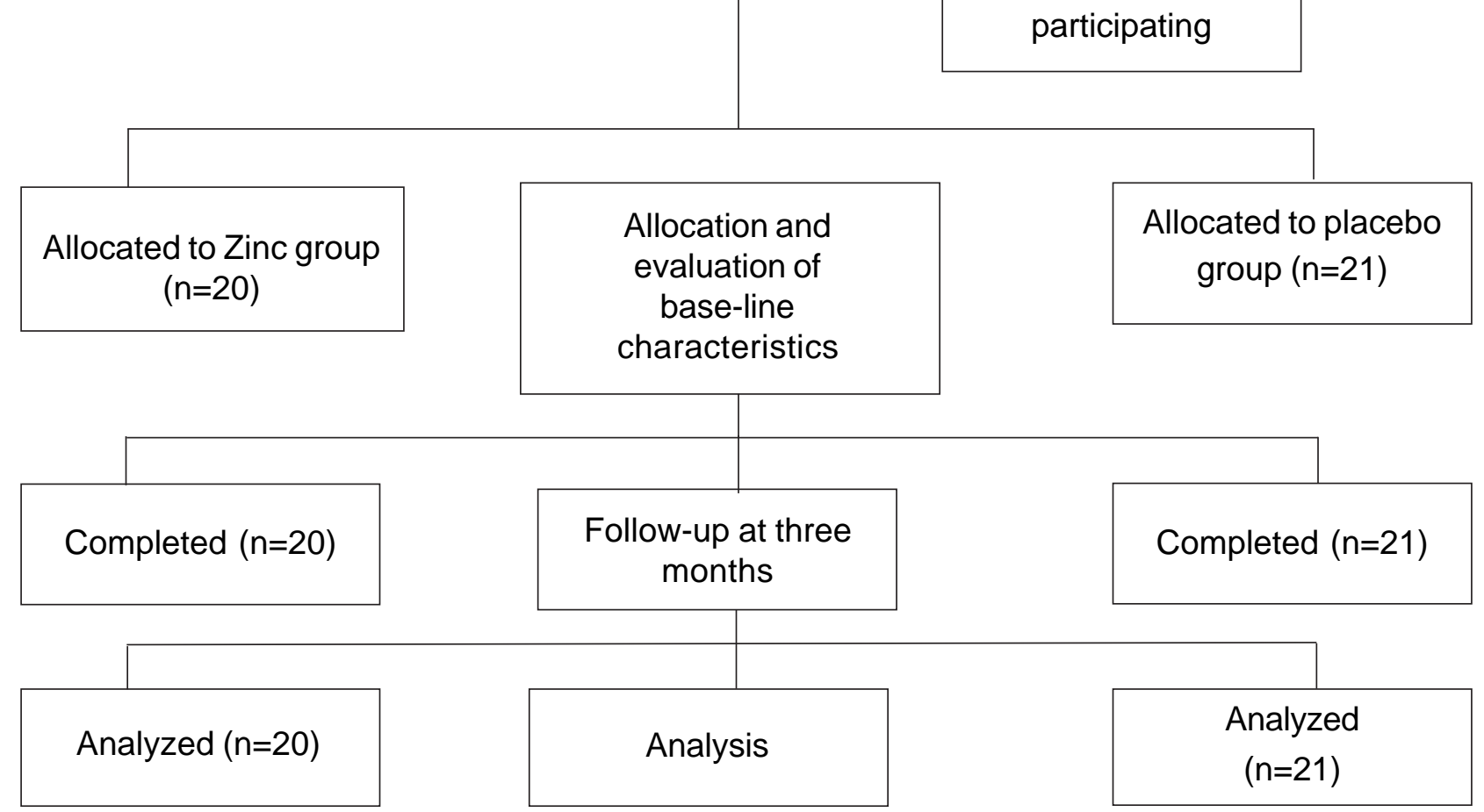

Figure 1. CONSORT flow diagram for the ZisCKDu-P trial. None of the participants discontinued during the study period. 


\section{Side effects}

Two patients in the treatment group and three patients in the placebo group complained of epigastric discomfort. None of the reported side effects were severe enough for termination of a study participant from the trial.

\section{Group comparison}

There were no significant interaction effects between the treatment arm and the placebo arm (Table 1). Adherence was found to be $88.2 \%$ vs. $87.8 \%$ in the placebo group vs. treatment group respectively.

\section{Changes in clinical characteristics and kidney function after three months of the intervention}

In the treatment group, none of the clinical, haematological parameters and kidney function were significantly changed after three months of the intervention. At the baseline vs. three months, mean eGFR; $40.9 \pm 10.4 \mathrm{~mL} / \mathrm{min} / 1.73 \mathrm{~m}^{2}$ vs. $39.7 \pm 9.2 \mathrm{~mL} /$ $\mathrm{min} / 1.73 \mathrm{~m}^{2}$ and mean UPCR; $65 \pm 54 \mathrm{mg} / \mathrm{mmol}$ vs. $82 \pm 86 \mathrm{mg} / \mathrm{mmol}$ (Table 2).
In the placebo group, BMI and diastolic blood pressures were significantly changed over three months of the intervention. At the baseline vs. three months, mean $\mathrm{BMI} ; 23 \pm 4 \mathrm{Kg} / \mathrm{m}^{2}$ vs. $22.7 \pm 3.9 \mathrm{Kg} / \mathrm{m}^{2}, \mathrm{P}=0.01$ and mean diastolic blood pressure; $78 \pm 6 \mathrm{mmHg}$ vs. $86 \pm 10$ $\mathrm{mmHg}, \mathrm{P}=0.001$ (Table 2).

Comparison of the two groups showed significant changes in diastolic blood pressure and blood hemoglobin level. Diastolic blood pressures were reduced by $0.25 \pm 3.5 \mathrm{mmHg}$ in the treatment group, while it was increased by $7.71 \pm 9.4 \mathrm{mmHg}$ in the placebo group, $P=0.01$. Blood haemoglobin level was found to be reduced by $0.33 \pm 1 \mathrm{~g} / \mathrm{dl}$ in the treatment group while it increased by $0.34 \pm 0.7 \mathrm{~g} / \mathrm{dl}$ in the placebo group, $P=0.02$. Changes of the eGFR values of the treatment group and the placebo group are shown in Figure 2 and Figure 3 respectively. Urine protein/creatinine ratios were found to be increased in both groups, treatment group vs. placebo group; $47 \pm 39 \mathrm{mg} / \mathrm{mmol} / \mathrm{l} \mathrm{vs} .189 \pm 205 \mathrm{mg} / \mathrm{mmol} / \mathrm{l}, P=0.48$ (Table 3).

Table 2. Clinical characteristics and kidney function at base line and after three months, in the treatment and placebo groups $(\mathrm{N}=20)$

\begin{tabular}{|c|c|c|c|c|c|c|}
\hline \multirow[b]{2}{*}{ Measure } & \multicolumn{3}{|c|}{ Treatment Group $(n=20)$} & \multicolumn{3}{|c|}{ Placebo Group ( $n=21)$} \\
\hline & $\begin{array}{c}\text { Baseline } \\
\text { Mean (SD) }\end{array}$ & $\begin{array}{c}\text { Three } \\
\text { months } \\
\text { Mean (SD) }\end{array}$ & $P$ Value & $\begin{array}{l}\text { Baseline } \\
\text { Mean (SD) }\end{array}$ & $\begin{array}{c}\text { Three } \\
\text { months } \\
\text { Mean (SD) }\end{array}$ & $P$ Value \\
\hline BMI $\left(\mathrm{Kg} / \mathrm{m}^{2}\right)$ & $21.5(3)$ & $21.4(3.1)$ & 0.67 & $23(4)$ & $22.7(3.9)$ & 0.01 \\
\hline $\begin{array}{l}\text { Diastolic pressure } \\
(\mathrm{mmHg})\end{array}$ & $79(10)$ & $79(4)$ & 0.75 & $78(6)$ & $86(10)$ & 0.001 \\
\hline $\begin{array}{l}\text { Systolic pressure } \\
(\mathrm{mmHg})\end{array}$ & $123(10)$ & $122(6)$ & 0.66 & $125(12)$ & $124(9)$ & 0.62 \\
\hline $\begin{array}{c}\text { Urine } \\
\text { protein/creatinine } \\
(\mathrm{mg} / \mathrm{mmol})\end{array}$ & $65(54)$ & $82(86)$ & 0.46 & 72.4 (113) & $120(209)$ & 0.36 \\
\hline Hemoglobin (g/dl) & $12(1)$ & $12(2)$ & 0.17 & $12.4(1.75)$ & $12.8(1.7)$ & 0.06 \\
\hline $\begin{array}{c}\text { eGFR } \\
\left(\mathrm{mL} / \mathrm{min} / 1.73 \mathrm{~m}^{2}\right)\end{array}$ & $40.9(10.4)$ & $39.7(9.2)$ & 0.31 & $37.1(6.8)$ & $36.4(10)$ & 0.63 \\
\hline
\end{tabular}




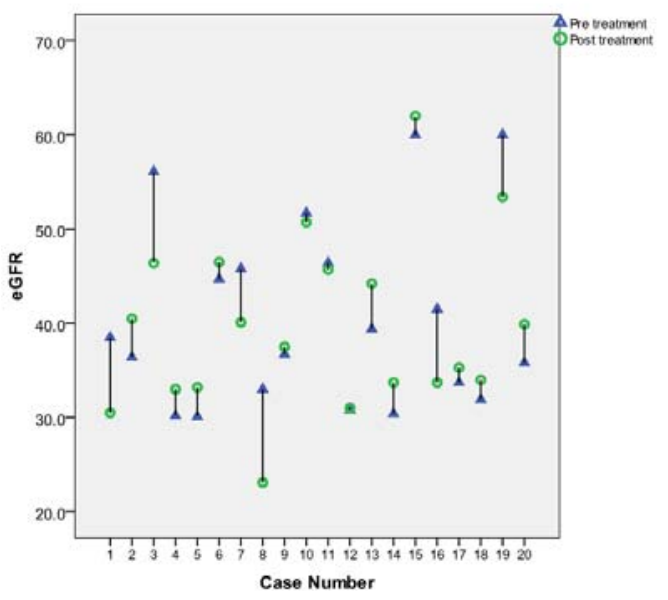

Figure 2. Pre-treatment and post-treatment estimated glomerular filtration rates in the treatment group.

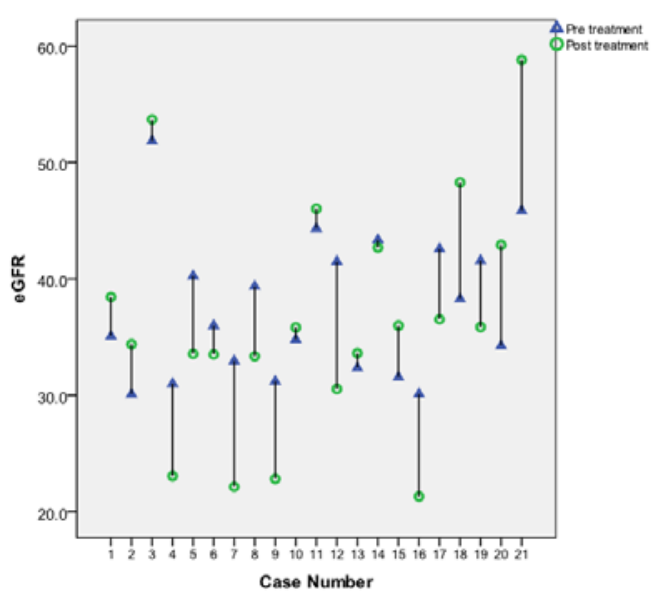

Figure 3. Pre-treatment and post-treatment estimated glomerular filtration rates in the placebo group.

Table 3. Comparison of changes in clinical characteristics and kidney function between treatment group and placebo group

\begin{tabular}{|c|c|c|c|c|}
\hline BMI $\left(\mathrm{Kg} / \mathrm{m}^{2}\right)$ & $N$ & \multicolumn{2}{|c|}{$\begin{array}{c}\text { Mean change over } \\
\text { three months } \\
\text { (baseline-three months) }\end{array}$} & $P$ \\
\hline Zinc Sulfate & 20 & 0.05 & \pm 0.56 & 0.17 \\
\hline Placebo & 21 & 0.27 & \pm 0.43 & \\
\hline \multicolumn{5}{|c|}{ Diastolic pressure $(\mathrm{mmHg})$} \\
\hline Zinc Sulfate & 20 & 0.25 & \pm 3.5 & 0.01 \\
\hline Placebo & 21 & -7.71 & \pm 9.4 & \\
\hline \multicolumn{5}{|c|}{ Systolic pressure (mmHg) } \\
\hline Zinc Sulfate & 20 & 0.9 & \pm 9.2 & 0.94 \\
\hline Placebo & 21 & 1.1 & \pm 10.4 & \\
\hline \multicolumn{5}{|c|}{ Urine protein/creatinine $(\mathrm{mg} / \mathrm{mmol})$} \\
\hline Zinc Sulfate & 20 & -47 & \pm 39 & 0.48 \\
\hline Placebo & 21 & -189 & \pm 205 & \\
\hline \multicolumn{5}{|l|}{ Hemoglobin (g/dl) } \\
\hline Zinc Sulfate & 20 & 0.33 & \pm 1 & 0.02 \\
\hline Placebo & 21 & -0.34 & \pm 0.7 & \\
\hline \multicolumn{5}{|l|}{$\begin{array}{c}\text { eGFR } \\
\left(\mathrm{mL} / \mathrm{min} / 1.73 \mathrm{~m}^{2}\right)\end{array}$} \\
\hline Zinc Sulfate & 20 & -1.16 & \pm 5 & 0.81 \\
\hline Placebo & 21 & -0.71 & \pm 6.8 & \\
\hline
\end{tabular}




\section{Discussion and conclusions}

In the ZisCKDu-P trial, mean age of the study population was $51.2 \pm 6.2$ years. Number of men recruited to the study was six times higher than the number of women. CKDu prevalence was higher among men in all divisional areas of North Central Province of Sri Lanka which ranged from 1.3:1 to 2.6:1.18 Epidemiological studies revealed that CKDu was common in the age group of 40 to 69 years and prevalence of CKDu stage 3 was three times higher among males. ${ }^{19}$ Advanced stages of the disease were frequently seen in men. ${ }^{20}$ Male predominance was more pronounced in the current study $(6: 1)$. The dissimilarity between male and female participants regarding social influences on decision making and participating in interventional studies may explain this difference. ${ }^{21}$

Oral zinc supplementation improves appetite and food intake in zinc deficient CKD patients. ${ }^{22,23}$ Therefore, oral zinc supplementation would have improved appetite and food intake in the study group. This may explain the finding that, while the BMI remained unchanged in the study group, there was a significant reduction of $\mathrm{BMI}$ in the placebo group.

A previous study showed that zinc level is inversely associated with diastolic blood pressures while there is no association with systolic blood pressures. ${ }^{24}$ In the current study significant increase in diastolic blood pressure was observed in the placebo arm while systolic blood pressure remained stable. Zinc supplementation reduces serum copper/ zinc ratios, which in turn reduce oxidative stress and inflammation. ${ }^{25}$ Antiinflammatory activity of zinc on arterial wall, may improve arterial stiffness and maintain stable diastolic blood pressure.

Mean hemoglobin level was found to be normal in both groups. Therefore, severe iron deficiency was unlikely to be present in the study population. Zinc deficiency may predispose to iron deficiency anemia in CKD. Considering zinc deficient state, supplementation of zinc with iron may improve iron absorption and hemoglobin level in CKD. ${ }^{26}$ In the ZisCKDu-P trial hemoglobin level showed a non-significant decline in the study group while there was a significant increase in the placebo group. Interaction of zinc with copper absorption may explain this finding. Copper and zinc interact at the intestinal mucosal level, affecting copper absorption. Zinc supplementation would have reduced copper absorption which is a crucial micronutrient for hemoglobin synthesis. ${ }^{10}$ Therefore, co-administration of copper and or iron guided by serum levels may ameliorate the unfavorable effect of zinc on hemoglobin.
There were minor side effects noted in the treatment group. Epigastric pain and reflux may represent treatment related side effects. ${ }^{10}$ None of the side effects was severe enough for termination of participants from the trial and this may signify the safety of the intervention.

Supplementation with zinc may improve arterial stiffness and maintain stable diastolic blood pressure and it shows favorable effects on BMI. The effects of oral zinc supplementation on nutritional status and hemoglobin level of CKDu patients should be further studied.

Measurement of serum zinc, copper and iron levels at baseline and follow up visit will be important in the hypothesis testing of a definitive study. Nonsignificant decline of haemoglobin in the treatment group would have been due to interactions of zinc with copper and iron. Co-administration of zinc with copper and or iron guided by serum levels, may be considered. It may ameliorate the possible unfavorable effects of zinc on copper and iron absorption. The hypothesis testing main study should test the effectiveness of same dose of zinc for a similar duration of treatment in a larger sample with a follow up period of one year. Measurement of UPCR and serum creatinine, at six months and one year following completion of treatment would be considered. The study subjects should be monitored for long term side effects of zinc supplementation for one year following the completion of the intervention.

\section{Conflict of interest}

The authors declare that there is no conflict of interest regarding the publication of this paper.

\section{Acknowledgments}

This work was supported by the "Dr Ranji Wickremanayake research grant for 2019"; Ceylon College of Physicians, Sri Lanka. We would like to acknowledge Mrs. GMMS Wijewardhane and Dr HMC Bandara for provision of accommodation during the study period.

\section{References}

1. Ranasinghe AV, Kumara GWGP, et al. The incidence, prevalence and trends of Chronic Kidney Disease and Chronic Kidney Disease of uncertain aetiology (CKDu) in the North Central Province of Sri Lanka: an analysis of 30,566 patients. BMC Nephrol. 2019; 20: 338.

2. Jayatilake N, Mendis S, Maheepala P, Mehta FR. Chronic kidney disease of uncertain aetiology: prevalence and 
causative factors in a developing country. BMC Nephrol. 2013; 14: 180.

3. Wimalawansa SJ. The role of ions, heavy metals, fluoride, and agrochemicals: critical evaluation of potential aetiological factors of chronic kidney disease of multifactorial origin (CKDmfo/CKDu) and recommendations for its eradication. Environ Geochem Health 2016; 38(3): 639-78.

4. Sharma B, Singh S, Siddiqi NJ. Biomedical implications of heavy metals induced imbalances in redox systems. Biomed Res Int. 2014; 2014: 640754.

5. Luo B, Lin Y, Jiang S, et al. Endoplasmic reticulum stress eIF2 $\alpha$-ATF4 pathway-mediated cyclooxygenase- 2 induction regulates cadmium-induced autophagy in kidney. Cell Death Dis. 2016; 7(6): e2251.

6. Escobedo-Monge MF, Ayala-Macedo G, Sakihara G, et al. Effects of Zinc Supplementation on Nutritional Status in Children with Chronic Kidney Disease: A Randomized Trial. Nutrients. 2019; 11(11).

7. Yonova D, Vazelov E, Tzatchev K. Zinc status in patients with chronic renal failure on conservative and peritoneal dialysis treatment. Hippokratia. 2012; 16(4): 356-9.

8. Waalkes MP, Kovatch R, Rehm S. Effect of chronic dietary zinc deficiency on cadmium toxicity and carcinogenesis in the male Wistar [Hsd: (WI)BR] rat. Toxicol Appl Pharmacol. 1991; 108(3): 448-56.

9. Hettiarachchi M, Liyanage C. Coexisting micronutrient deficiencies among Sri Lankan pre-school children: a community-based study. Matern Child Nutr. 2012; 8(2): 259-66.

10. Micronutrients loMUPo. Dietary Reference Intakes for Vitamin A, Vitamin K, Arsenic, Boron, Chromium, Copper, lodine, Iron, Manganese, Molybdenum, Nickel, Silicon, Vanadium, and Zinc. Washington (DC): National Academies Press (US); 2001.

11. Kapil U, Verma D, Goel M, etal. Dietary intake of trace elements and minerals among adults in underprivileged communities of rural Rajasthan, India. Asia Pac J Clin Nutr. 1998; 7(1): 29-32.

12. Khan MI, Siddique KU, Ashfaq F, Ali W, Reddy HD, MishraA. Effect of high-dose zinc supplementation with oral hypoglycemic agents on glycemic control and inflammation in type-2 diabetic nephropathy patients. J Nat Sci Biol Med. 2013; 4(2): 336-40.

13. Ranasinghe P, Wathurapatha WS, Galappatthy P, Katulanda $P$, Jayawardena R, Constantine GR. Zinc supplementation in prediabetes: Arandomized double-blind placebo-controlled clinical trial. J Diabetes. 2018; 10(5): 386-97.
14. Ministry of Health Circular No. Epid/392/2008/25 dated February $10^{\text {th }}, 2009$.

15. Saper RB, Rash R. Zinc: an essential micronutrient. $A m$ Fam Physician. 2009; 79(9): 768-772.

16. Wapnir RA, Balkman C. Inhibition of copper absorption by zinc. Effect of histidine. Biol Trace Elem Res. 1991; 29(3): 193-202.

17. Myint ZW, Oo TH, Thein KZ, Tun AM, Saeed H. Copper deficiency anemia: review article. Ann Hematol. 2018; 97(9): 1527-34.

18. Ranasinghe AV, Kumara GWGP, Karunarathna RH, et al. The incidence, prevalence and trends of Chronic Kidney Disease and Chronic Kidney Disease of uncertain aetiology (CKDu) in the North Central Province of Sri Lanka: an analysis of 30,566 patients. BMC Nephrol. 2019; 20(1): 338.

19. Rajapakse S, Shivanthan MC, Selvarajah M. Chronic kidney disease of unknown etiology in Sri Lanka. Int J Occup Environ Health. 2016; 22(3): 259-64.

20. Ruwanpathirana T, Senanayake S, Gunawardana N, et al. Prevalence and risk factors for impaired kidney function in the district of Anuradhapura, Sri Lanka: a cross-sectional population-representative survey in those at risk of chronic kidney disease of unknown aetiology. BMC Public Health. 2019; 19(1): 763.

21. Lobato L, Bethony JM, Pereira FB, Grahek SL, Diemert D, Gazzinelli MF. Impact of gender on the decision to participate in a clinical trial: a cross-sectional study. BMC Public Health. 2014; 14: 1156.

22. Sahin H, Uyanik F, Inanç N, Erdem O. Serum zinc, plasma ghrelin, leptin levels, selected biochemical parameters and nutritional status in malnourished hemodialysis patients. Biol Trace Elem Res. 2009; 127(3): 191-9.

23. El-ShazlyAN, Ibrahim SA, El-Mashad GM, Sabry JH, Sherbini NS. Effect of zinc supplementation on body mass index and serum levels of zinc and leptin in pediatric hemodialysis patients. Int J Nephrol Renovasc Dis. 2015; 8: 159-63.

24. Darroudi S, Saberi-Karimian M, Tayefi M, Tayefi B, Khashyarmanesh Z, Fereydouni N, et al. Association Between Hypertension in Healthy Participants and Zinc and Copper Status: a Population-Based Study. Biol Trace Elem Res. 2019; 190(1): 38-44.

25. Guo $\mathrm{CH}$, Wang $\mathrm{CL}$. Effects of zinc supplementation on plasma copper/zinc ratios, oxidative stress, and immunological status in hemodialysis patients. Int J Med Sci. 2013; 10(1): 79-89.

26. Abdelhaleim, Abdo Soliman JS, Amer AY. Association of Zinc Deficiency with Iron Deficiency Anemia and its Symptoms: Results from a Case-control Study. Cureus 2019; 11(1): e3811. 